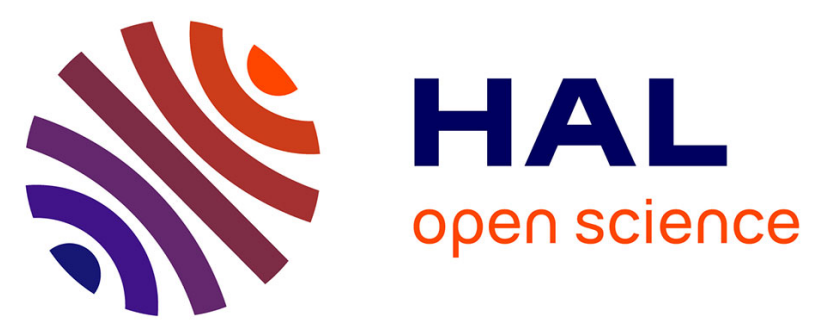

\title{
Development of High-Speed Image Acquisition Systems for Spray Characterization Based on Single-Droplet Experiments
}

Sofija Vulgarakis-Minov, Frédéric Cointault, Jürgen Vangeyte, J.G. Pieters, David Nuyttens

\section{To cite this version:}

Sofija Vulgarakis-Minov, Frédéric Cointault, Jürgen Vangeyte, J.G. Pieters, David Nuyttens. Development of High-Speed Image Acquisition Systems for Spray Characterization Based on Single-Droplet Experiments. Transactions of the ASABE, 2015, 58 (1), pp. 27 - 37. 10.13031/trans.58.10775 . hal-01774293

\section{HAL Id: hal-01774293 \\ https://institut-agro-dijon.hal.science/hal-01774293}

Submitted on 27 May 2020

HAL is a multi-disciplinary open access archive for the deposit and dissemination of scientific research documents, whether they are published or not. The documents may come from teaching and research institutions in France or abroad, or from public or private research centers.
L'archive ouverte pluridisciplinaire HAL, est destinée au dépôt et à la diffusion de documents scientifiques de niveau recherche, publiés ou non, émanant des établissements d'enseignement et de recherche français ou étrangers, des laboratoires publics ou privés. 


\title{
DEVELOPMENT OF HIGH-SPEED IMAGE ACQUISITION SYSTEMS FOR SPRAY CHARACTERIZATION BASED ON SINGLE-DROPLET EXPERIMENTS
}

\author{
S. Vulgarakis Minov, F. Cointault, J. Vangeyte, J. G. Pieters, D. Nuyttens
}

\begin{abstract}
Accurate spray and droplet characterization is important for increased understanding of the pesticide spray application process. The goal of this study was to develop two image acquisition systems based on single-droplet experiments using a piezoelectric single-droplet generator and a high-speed imaging technique, which will be used in a later stage of this study to evaluate micro and macro spray characteristics and droplet impact behavior. Experiments with different camera settings, lenses, diffusers, and light sources and the resulting image quality parameters showed the necessity of having a good image acquisition and processing system. The image analysis results contributed to selecting the optimal setup for measuring droplet size and velocity, which consisted of a high-speed camera with $6 \mu$ s exposure time, a microscope lens at a working distance of $430 \mathrm{~mm}$ resulting in a field of view of $10.5 \mathrm{~mm} \times 8.4 \mathrm{~mm}$, and a xenon backlight without a diffuser. The high-speed camera with a macro video zoom lens at a working distance of $143 \mathrm{~mm}$ with a larger field of view $(88 \mathrm{~mm} \times 110 \mathrm{~mm})$ in combination with a halogen spotlight with a diffuser was found to have the best potential for measuring macro spray characteristics, such as the droplet trajectory, spray angle, and spray shape.
\end{abstract}

Keywords. Droplet characteristics, Droplet generator, Image processing.

T The characteristics of pesticide sprays generated by agricultural nozzles play an important role in the application accuracy and efficiency of plant protection products in precision agriculture (Stafford, 2000). Poor accuracy and spray losses may reduce the effectiveness of the application and increase environmental contamination and operator risk. The challenge is to reduce spray losses during transport to the target and maximize spray deposition and efficacy, thus improving the spray application process (Zabkiewicz, 2007). The most important spray characteristics influencing the pesticide application process are droplet size and velocity, spray volume distribution pattern, liquid sheet length and thickness, the structure of individual droplets, and the 3D spray dimensions (Miller and Ellis, 2000; Nuyttens et al., 2009a).

In the past, intrusive methods, also called sampling techniques, were mainly used for spray characterization. With these techniques, droplets were collected and analyzed using mechanical sampling devices. However, these sampling devices may affect the spray flow behavior and

Submitted for review in May 2014 as manuscript number MS 10775; approved for publication by the Machinery Systems Community of ASABE in December 2014.

The authors are Sofija Vulgarakis Minov, Electrical Engineer, Institute for Agricultural and Fisheries Research (ILVO), Merelbeke, Belgium; Frédéric Cointault, Professor, AgroSup, Dijon, France; Jürgen Vangeyte, Agricultural Engineer, ILVO, Merelbeke, Belgium; Jan G. Pieters, ASABE Member, Professor, Department of Biosystems Engineering, Ghent University, Ghent, Belgium; David Nuyttens, ASABE Member, Agricultural Engineer, ILVO, Merelbeke, Belgium. Corresponding author: David Nuyttens, ILVO, Burg. Van Gansberghelaan 115, bus 1, 9820 Merelbeke, Belgium; phone: +32-9-27227-82; e-mail: david.nuyttens@ilvo.vlaanderen.be. can only be used to evaluate spray deposition and estimate droplet size (Lefebvre, 1989; Rhodes, 1998).

Due to the development of modern technology, such as powerful computers, lasers, cameras, and automation systems, quantitative optical non-imaging light scattering spray characterization techniques have been developed for non-intrusive spray characterization. These techniques do not disturb the spray process and are based on light-matter interaction. The most important types of non-imaging light scattering droplet characterization techniques are phase Doppler particle analyzers (PDPA) (Nuyttens et al., 2007, 2009b), laser diffraction analyzers, e.g., the Malvern analyzer (Stainier et al., 2006), and optical array probes (Teske et al., 2000). Although these techniques are able to measure droplet sizes and/or velocities, none of them are able to fully characterize the spray characteristics or study droplet impact behavior. Moreover, these techniques are complex, expensive, and (in most cases) limited to small measuring volumes. Additionally, several studies have shown a wide variation in mean droplet size for the same nozzle specifications when using different techniques (Nuyttens et al., 2007). The limitations of non-imaging techniques, recent improvements in digital image processing, the sensitivity of imaging systems, and cost reductions have increased the interest in imaging techniques for agricultural applications, specifically for pesticide applications, as summarized by Hijazi et al. (2012). Imaging analyzers are spatial sampling techniques consisting of a light source, a camera, and a computer with image acquisition and processing software. The small droplet size and the high velocity of the ejected droplets require a high-quality camera as well as a very bright, homogeneous light source for accurate characteriza- 
tion (Cointault et al., 2002). For tracking high-speed particles, two imaging techniques can be used: the multiexposure technique and the high-speed technique.

The multi-exposure technique combines a highresolution standard camera with a strobe light for tracking high-speed particles (Cointault et al., 2002; Fan et al., 2008; Hijazi et al., 2010; Li et al., 2010; Vangeyte, 2013). The principle is that a series of light flashes is triggered one after another in a single camera exposure. The number of flashes determines the maximum number of particle positions that can be recorded on each image. This technique was used by Reichard et al. (1998) to analyze single-droplet behavior by combining a monochrome video camera (60 fps) with a single backlight stroboscope (type 1538-A, Genrad, Concord, Mass.) at a flash rate of about seven times the field-sequential rate used to drive the camera. Lad et al. (2011) used a high-intensity pulsed laser $(200 \mathrm{~mJ}$, $532 \mathrm{~nm}$ ) as a backlight, which was synchronized with a firewire digital camera $(1280 \times 960$ pixels $)$ to analyze spray characteristics. The laser beam was converted to a laser cone using a concave lens and then diffused. A $200 \mathrm{~mm}$ micro-lens equipped with a spacer provided a magnification of 2.6, resulting in a field of view (FOV) of $1.82 \mathrm{~mm} \times$ $1.36 \mathrm{~mm}$ at a working distance of $250 \mathrm{~mm}$. The digital camera captured shadow images, which were analyzed to determine droplet sizes. Malot and Blaisot (2000) developed a particle sizing method based on incoherent backlight images using a stroboscope with two fibers synchronized with two cameras. This technique was used to project images of droplets on a video camera, which led to twodimensional images.

The high-speed technique is an alternative method to analyze spray characteristics using a high-speed camera and combining high-resolution images with a high frame rate (1000 fps and more) (Kim et al., 2011). Because of the short exposure time inherent to high-speed imaging, high illumination intensities are needed. The usual method used to illuminate the spray is powerful background illumination, either with a xenon light (Kashdan et al., 2007) or with power LEDs (Massinon and Lebeau, 2012). The advantages of this method are the possibility of modifying the number of frames per second and the high resolution of the images. Massinon and Lebeau (2012) and Zwertvaegher et al. (2014) used a high-speed camera (Y4 CMOS, IDT, Lommel, Belgium) with a high-magnification lens $(12 \times$ zoom Navitar, $341 \mathrm{~mm}$ working distance) coupled with a high-power LED lighting to study the droplet impacts and spray retention of a real spray application. The camera resolution was reduced to $1016 \times 185$ pixels to achieve a frame rate of 20,000 fps with a spatial resolution of $10.58 \mu \mathrm{m}$ per pixel. A backlight consisting of 19 LEDs with a beam angle of $12.5^{\circ}$ was placed $0.50 \mathrm{~m}$ behind the focus area to provide high illumination and a uniform background for the images. Many others, including Šikalo et al. (2005), studied droplet impacts with a high-speed CCD camera; however, in these studies, single droplets were produced using a microdrop generator in the ondemand or continuous mode. Because spray droplets are fast, translucent, and their diameters cover a wide range (from 10 to $1000 \mu \mathrm{m}$ ), droplet measurement accuracy strongly depends on the imaging and optical setup.

The aim of this study was to develop two image acquisition systems based on images of single droplets generated with a piezoelectric droplet generator in the on-demand mode (Switzer, 1991; Yang et al., 1997; Lee, 2002). Different high-speed camera settings, illuminations, diffusers, and lenses were tested using shadowgraph (background) imaging (Lecuona et al., 2000; Castanet et al., 2013) and evaluated based on three defined image quality parameters (entropy ratio, contrast ratio, and signal-to-noise ratio), the light stability and overexposure ratio, and the measurement accuracy. In a later stage of this study, the developed image acquisition systems will be used to characterize the micro (droplet size and velocity) and macro (spray angle, liquid sheet length, and droplet trajectory) spray characteristics of real pesticide sprays.

The remainder of this article comprises three sections. The following Materials and Methods section introduces the piezoelectric droplet generator, the image acquisition system, and the image analysis process based on the image quality parameters, the light stability and overexposure time, and the accuracy of the droplet size measurement. The subsequent section contains the results and a discussion of the image analysis, and the final section concludes the article.

\section{Materials AND Methods PiezoeleCtric Droplet Generator}

A piezoelectric droplet generator (Gembloux Agro-BioTech, Université de Liége, Belgium) (fig. 1 top) able to form uniform droplets in two modes, i.e., droplet-ondemand (DOD) and continuous mode (Rayleigh breakup), was used. In this study, single droplet formation was done in DOD mode, which is based on acoustic wave theory (Yang et al., 1997) and relies on double pulse width values, i.e., absorption time $\left(t_{a}, \mathrm{~ms}\right)$ and pulsation time $\left(t_{p}, \mathrm{~ms}\right)$, and the voltage pulse amplitude $\left( \pm V_{p}, \mathrm{~V}\right)$ (fig. 1 bottom), which were applied using LabView software (National Instruments, Austin, Tex.). Applying a double voltage pulse to the piezoelectric element forces a droplet out of the nozzle. A positive voltage sent to the piezoelectric element results in absorption (Lam et al., 2009), and a negative voltage results in pressure in the ejection chamber. In this study, droplets were generated in DOD mode using a glass nozzle (fig. 1 top) with a $123 \mu \mathrm{m}$ orifice size at $t_{a}=0.4 \mathrm{~ms}, t_{p}=$ $50 \mathrm{~ms}$, and $V_{p}= \pm 4.5 \mathrm{~V}$.

\section{IMAGE ACQUISITION SYSTEM}

The image acquisition system consisted of a high-speed (HS) camera and a high-power backlight (fig. 2). An overview of the different lenses, illumination systems, and exposure times tested is given in table 1. The software package Motion Studio (version 2.09, 2011, IDT, Lommel, Belgium) was used as a frame capture device for choosing the settings of the HS camera, including frame rate, record mode, sensor gain, image resolution, and exposure mode.

An N3 HS camera (IDT, Lommel, Belgium) with a $25.4 \mathrm{~mm}$ (1 in.) CMOS sensor and $12 \mu \mathrm{m}$ pixel resolution 


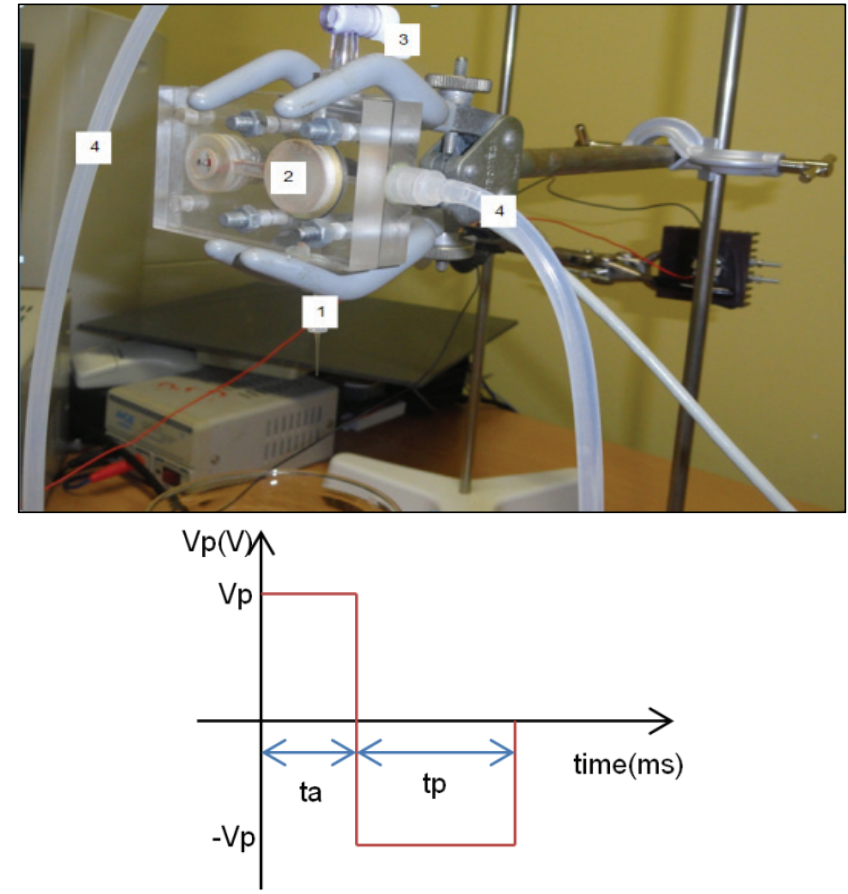

Figure 1. (top) Piezoelectric droplet generator $(1=$ glass nozzle, $2=$ piezoelectric element, $3=$ clamp, and $4=$ tubes) and (bottom) schematic of the rectangular double pulse used to generate droplets: $t_{a}=$ absorption time, $t_{p}=$ pulsation time, and $\pm V_{p}=$ pulse amplitude voltage set in LabView.
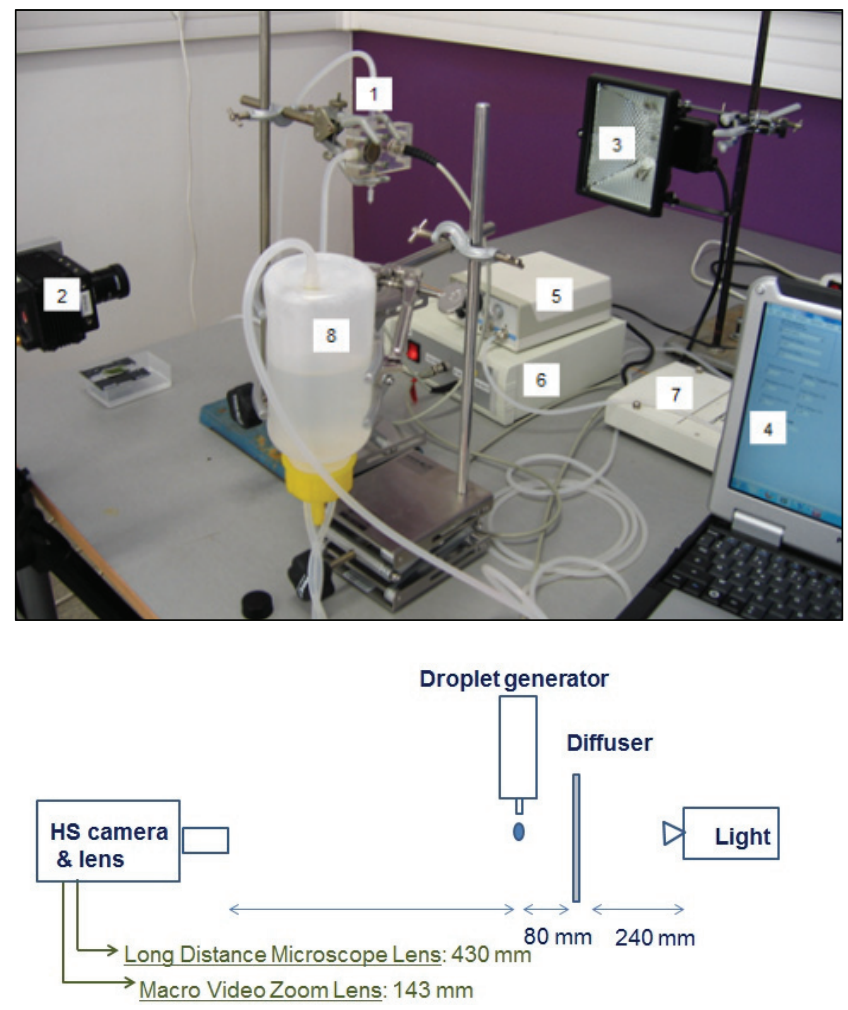

Figure 2. (top) Image acquisition system $(1=$ droplet generator with piezoelectric element, $2=$ high-speed camera and lens, $3=$ light source, 4 = computer with frame software, $5=$ pressure supply, $6=$ signal amplifier, $7=$ pulse generator, and $8=$ liquid tank) and (bottom) schematic of the system.
Table 1. Summary of the tested image acquisition setups.

\begin{tabular}{|c|c|c|c|}
\hline Lens & $\begin{array}{l}\text { Light } \\
\text { Source }\end{array}$ & Diffuser & $\begin{array}{c}\text { Exposure Time } \\
(\mu s)\end{array}$ \\
\hline \multirow{6}{*}{$\begin{array}{l}\text { Macro video } \\
\text { zoom lens }\end{array}$} & Seven-Star & 120 grit & \\
\hline & LED & $\begin{array}{l}220 \text { grit } \\
\text { None }\end{array}$ & 5,10 , and 15 \\
\hline & Halogen & 120 grit & \\
\hline & spotlight & $\begin{array}{l}220 \text { grit } \\
\text { None }\end{array}$ & 5,10 , and 15 \\
\hline & Xenon & 120 grit & \\
\hline & lamp & $\begin{array}{l}220 \text { grit } \\
\text { None }\end{array}$ & 5,10 , and 15 \\
\hline \multirow{6}{*}{$\begin{array}{c}\mathrm{K} 2 / \mathrm{SC} \\
\text { long-distance } \\
\text { microscope } \\
\text { system }\end{array}$} & Seven-Star & 120 grit & \\
\hline & LED & $\begin{array}{l}220 \text { grit } \\
\text { None }\end{array}$ & 5,10 , and 15 \\
\hline & Halogen & 120 grit & \\
\hline & spotlight & $\begin{array}{l}220 \text { grit } \\
\text { None }\end{array}$ & 5,10 , and 15 \\
\hline & Xenon & 120 grit & \\
\hline & lamp & $\begin{array}{l}220 \text { grit } \\
\text { None }^{[\mathrm{a}]}\end{array}$ & 5,10 , and 15 \\
\hline
\end{tabular}

set to $1000 \mathrm{~Hz}$ with a $+3 \mathrm{~dB}$ sensor gain was used (Massinon and Lebeau, 2012). Exposure times were set at 5,10 , and $15 \mu$ s and additionally at $6,7,8$, and $9 \mu$ s for the xenon light in combination with the $\mathrm{K} 2 / \mathrm{SC}$ long-distance microscope lens without a diffuser (table 1). In order to image a droplet, the droplet ejection was triggered with the camera.

For each of the 58 combinations of lens, light source, diffuser, and exposure time (table 1), droplet ejection videos with 100 images were taken. When a droplet could be detected visually in these videos, ten consecutive images with a droplet were selected for image analysis. Similarly, ten consecutive images without a droplet were also selected from these videos for further image analysis.

Two types of lenses were evaluated. A macro video zoom lens (18 to $108 \mathrm{~mm}$ focal length, F/2.5 to closed, $2 / 3$ in. format, Thales Optem, Fairport, N.Y.) with a closeup lens was used (Kim et al., 2011) at a working distance of $143 \mathrm{~mm}$, resulting in an FOV of $88 \mathrm{~mm} \times 110 \mathrm{~mm}$. To achieve a small FOV and to measure droplet characteristics in an accurate way, a K2/SC long-distance microscope lens (Infinity Photo-Optical Co., Boulder, Colo.), (Riefler and Wriedt, 2008) was used with a CF1 objective attached directly to its front. At a working distance of $430 \mathrm{~mm}$, an FOV of $10.5 \mathrm{~mm} \times 8.4 \mathrm{~mm}$ was obtained (Infinity, 2009). For all tests, the distances between the nozzle and the light, between the nozzle and the diffuser, and between the diffuser and the illumination source were 320, 80, and $240 \mathrm{~mm}$, respectively (fig. 2 bottom).

Knowing that spray droplet velocities can be in the range of 1 to $15 \mathrm{~m} \mathrm{~s}^{-1}$ (Nuyttens et al., 2007), the exposure time should be in the range of microseconds, thus requiring high illumination intensities (Ju et al., 2012). Moreover, the illumination should be stable, which requires a precisely controlled supply voltage. Therefore, three types of light source were tested with and without two types of diffuser (table 1). First, a Seven-Star power LED assembly (40 mm round, 5650 K, 14 W, Philips Lumileds, San Jose, Cal.) with a polymer 264 lens and DC power supply delivering $1645 \mathrm{~lm}$ at $700 \mathrm{~mA}$ (Sunrise Power Transformers GmbH, 
Hamburg, Germany) was tested. Second, a halogen spotlight $(350 \mathrm{~W}$, EcoHalo, Koninklijke Philips Amsterdam, The Netherlands) (Ulmke et al., 2001) with a maximum power of $500 \mathrm{~W}$ and a working temperature of $3200 \mathrm{~K}$ was included in the tests. The spotlight is the least expensive light source, but care must be taken not to overheat any object in the recorded zone. Finally, a xenon short arc lamp (model 5132, $300 \mathrm{~W}$, Richard Wolf GmbH, Knittlingen, Germany) fed to the head by a flexible light conductor was selected for the purpose of achieving a clear image even at a very short exposure time (Kim et al., 2011). This type of light source is easy to handle and capable of providing instant high-power white light and a high-intensity continuous spectrum with low heat buildup.

A simple and effective way of reducing light inhomogeneity involves the use of a diffuser placed between the light and the lens (Kashdan et al., 2007; Lad et al., 2011) (fig. 2 bottom). Two types of ground-glass diffusers (Techspec, Edmund Optics, Barrington, N.J.) were used: 120 grit and 220 grit sandblast, both with a thickness of $1.6 \mathrm{~mm}$ and a size of $250 \mathrm{~mm} \times 250 \mathrm{~mm}$.

\section{IMAGE ANALYSIS}

Image analysis combines techniques and measurements based on the gray-level intensities of the image pixels and was used here to determine the imaging characteristics of the different image acquisition setups using image histograms. From the histograms, different first-order statistical properties (Materka and Strzelecki, 1998) of images taken with and without droplets were determined and used for comparison of the different image acquisition setups.

As the $N \times M$ image (region) is a function $f(x, y)$ of two variables $x$ and $y$, where $x=0,1, \ldots, N-1$, and $y=0,1, \ldots$, $M-1$, the function $f(x, y)$ can take discrete values $i=0,1, \ldots$, $L-1$, where $L$ is the total number of intensity levels in the image. Furthermore, an intensity level histogram shows the number of pixels in the image (region) that have a given intensity level:

$$
h(i)=\sum_{x=0}^{N-1} \sum_{y=0}^{M-1} \delta(f(x, y), i)
$$

where $\delta(j, i)$ is the Kronecker delta function:

$$
\delta(j, i)=\left\{\begin{array}{l}
1, j=i \\
0, j \neq i
\end{array}\right.
$$

Dividing the $h(i)$ values by the total number of pixels in the image (region), we obtain the approximate probability density of occurrence of the intensity levels (Tuceryan and Jain, 1998):

$$
p(i)=\frac{h(i)}{N \times M}, i=0,1, \ldots, L-1
$$

The first-order statistical properties used to assess the imaging characteristics of the image acquisition setups were the average gray level or mean, the average contrast or standard deviation, and the entropy (Haralic et al., 1973; Gonzalez et al., 2004) (table 2). These values were calculated for a defined region of interest (ROI) for all the images with a droplet as well as for all the images without a droplet using an image processing program developed in Matlab (The MathWorks, Inc., Natick, Mass.) that is divided into three steps: (1) selecting the ROI in an image, (2) showing the ROI image histogram, and (3) calculating the first-order statistical properties of the chosen ROI. The flowchart in figure 3 shows the process for determining the first-order statistical properties. For the macro video zoom lens, the ROI was defined as a region starting $5.0 \mathrm{~mm}$ below the nozzle with a size of $17.5 \mathrm{~mm} \times 45 \mathrm{~mm}$ (fig. $4 \mathrm{a}$ ). For the K2/SC longdistance microscope lens, the ROI started at $0.8 \mathrm{~mm}$ below the nozzle with a size of $2.5 \mathrm{~mm} \times 8.0 \mathrm{~mm}$ (fig. 4b). In both cases, the ROI was large enough to capture the same droplet in at least ten consecutive images.

For the specific purpose of comparing the different image acquisition setups, three image quality parameters for the ROI were defined and calculated from the first-order statistical properties:

Table 2. First-order statistical equations.

\begin{tabular}{cll}
\hline Parameter & Expression $^{[\mathrm{a}]}$ & Description \\
\hline $\begin{array}{c}\text { Mean } \\
\text { (average gray level) }\end{array}$ & $f_{1}=\mu=\sum_{i=0}^{L-1} i p(i)$ & A measure of the average gray level of an image and indicating the brightness. \\
\hline $\begin{array}{c}\text { Standard deviation } \\
\text { (average contrast) }\end{array}$ & $f_{2}=\sigma=\sqrt{\sum_{i=0}^{L-1} p(i)(i-\mu)^{2}}$ & $\begin{array}{l}\text { A measure of how much the gray level of pixels differs from the mean value to } \\
\text { detect if there are any substantial light or dark spots in the image. }\end{array}$ \\
\hline Entropy & $f_{3}=e=-\sum_{i=0}^{L-1} p(i) \log _{2} p(i)$ & $\begin{array}{l}\text { A measure of disorder: a high entropy value indicates the presence of an object, } \\
\text { whereas a } 0 \text { value corresponds to a constant image. }\end{array}$ \\
\hline
\end{tabular}

[a] $L$ is the number of quantized gray levels: $L=2^{B}$, where $B$ is the number of bits.

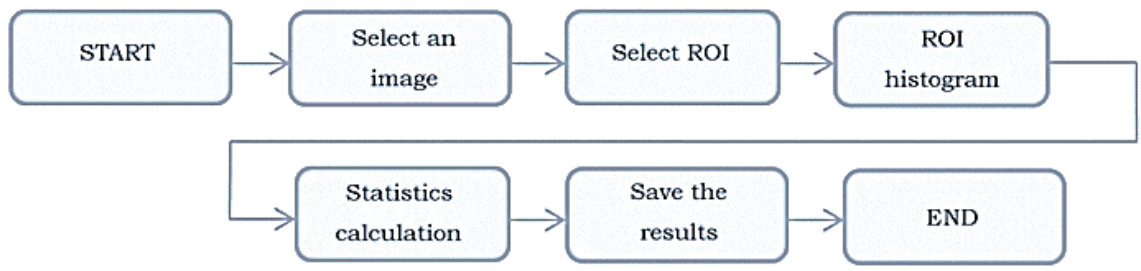

Figure 3. Flowchart of the first-order statistics algorithm. 


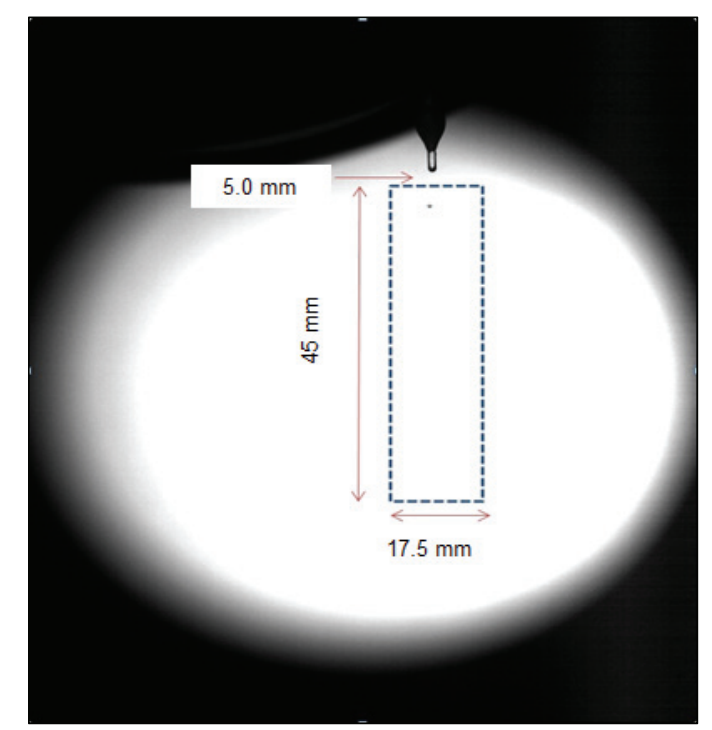

(a)

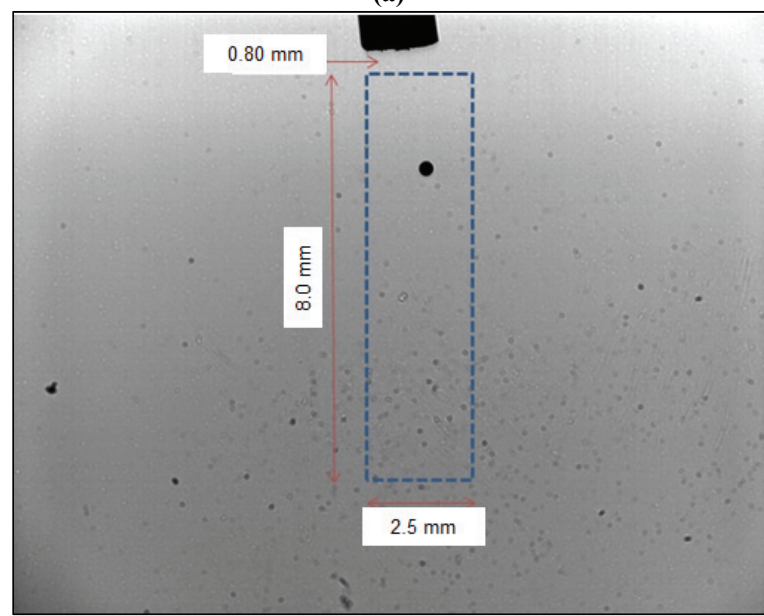

(b)

Figure 4. Region of interest (ROI) (blue dotted rectangle): (a) with the macro video zoom lens and xenon light with 120 grit diffuser at $15 \mu \mathrm{s}$ exposure time, and (b) with the K2/SC long-distance microscope lens and xenon light without a diffuser at $5 \mu$ s exposure time.

\section{Entropy Ratio}

Defined as the ratio of the entropy values from images with a droplet and without a droplet taken with the same image acquisition setup, the entropy ratio should be maximized, as we are aiming for maximal entropy in images with a droplet and minimal entropy in images without a droplet.

\section{Contrast Ratio}

Defined as the ratio of the average contrast values from images with a droplet and without a droplet taken with the same image acquisition setup, the contrast ratio should be maximized, as we are aiming for maximal contrast in images with a droplet and minimal contrast in images without a droplet.

\section{Signal-to-Noise Ratio (SNR)}

Defined as the ratio between the mean (signal) and the standard deviation (or average contrast) for images with a droplet, the SNR should be maximized, as we are aiming for a large signal value and a small noise value in images with a droplet.
Based on the image quality parameters, four image acquisition setups were selected, and their light stability and overexposure ratio were assessed by comparing histograms of the pixel intensity values of ten consecutive ROI images taken at the same settings without a droplet.

\section{ACCuracy of the Droplet Size Measurement}

In order to determine the correct droplet size and ensure measurement accuracy, the exact pixel size must be known for both lenses. For the macro video zoom lens, the focal length and pixel size were calculated with the following equations:

$$
\begin{gathered}
\text { Focal length }=\frac{\text { Working distance } \times \text { CMOS width }}{\text { Object width }+ \text { CMOS width }} \\
\text { Pixel size }=\frac{\text { Camera pixel resolution } \times \text { Working distance }}{\text { Focal length }}
\end{gathered}
$$

where the CMOS width for this $25.4 \mathrm{~mm}$ (1 in.) camera sensor was $12.8 \mathrm{~mm}$ (www.idtvision.com).

For the K2/SC long-distance microscope lens, multiple images of a Halcon ceramic calibration plate $(2.5 \mathrm{~mm} \times$ $2.5 \mathrm{~mm}$ ) were taken to ensure coverage of the whole FOV using the xenon light as a front light. The resulting images were processed with HDevelop software (version 8.0, MVTec Software GmbH, Munich, Germany) to determine the actual pixel size.

The size of the droplets produced in the DOD mode with the droplet generator was measured using the image processing algorithms developed by Vulgarakis Minov et al. (2013, 2014). To validate the droplet size measurement accuracy of the imaging system, the measured value was compared with the actual droplet size by collecting and weighing 100 droplets at the same nozzle settings in a Petri dish. The Petri dish was covered with Parafilm during this test to prevent evaporation. The test was performed in a climate-controlled room at $20^{\circ} \mathrm{C}$ and $47 \% \mathrm{RH}$. The measurement was repeated five times.

\section{Statistical Analysis}

The statistical analysis was carried out separately for each of the two lenses. To test the effects of different combinations of the two diffusers and no diffuser, the exposure times, and the three lighting systems (independent variables) on the entropy ratio, contrast ratio, and SNR (dependent variables), an analysis of variance (ANOVA) was performed. In addition to the main effects, all two-way and three-way interactions were tested. A p-value of 0.05 was considered statistically significant. Non-significant interactions were removed from the model. The test was performed in SPSS Statistics 19 (IBM, Armonk, N.Y.). Significant differences were assessed using the Scheffé and Student-Newman-Keuls (SNK) post hoc tests.

\section{RESULTS AND DISCUSSION}

The different image acquisition systems were evaluated based on the following criteria: image quality parameters (including entropy ratio, contrast ratio, and SNR), light 
stability and overexposure ratio, and accuracy of the droplet size measurement.

\section{IMAge QUALity PARAMETers}

Entropy ratio, contrast ratio, and SNR for the different image acquisition systems are presented in figure 5 for the macro video zoom lens and in figure 6 for the K2/SC longdistance microscope lens. For the macro video zoom lens (fig. 5), no significant effect on the entropy ratio of the three-way interaction light $\times$ diffuser $\times$ exposure time $(\mathrm{p}=$ 0.077 ) was found, but the two-way interactions light $\times$ diffuser $(p=0.019)$ and light $\times$ exposure time $(p<0.001)$ did have significant effects. For the two-way interaction diffuser $\times$ exposure time, a p-value of 0.06 was found. Post hoc tests revealed that, at $15 \mu \mathrm{s}$ exposure time, the combinations spotlight $\times 120$ grit diffuser and spotlight $\times 220$ grit diffuser had significantly higher entropy ratios than the other combinations. For these two image acquisition setups, no significant difference in entropy ratio was found.
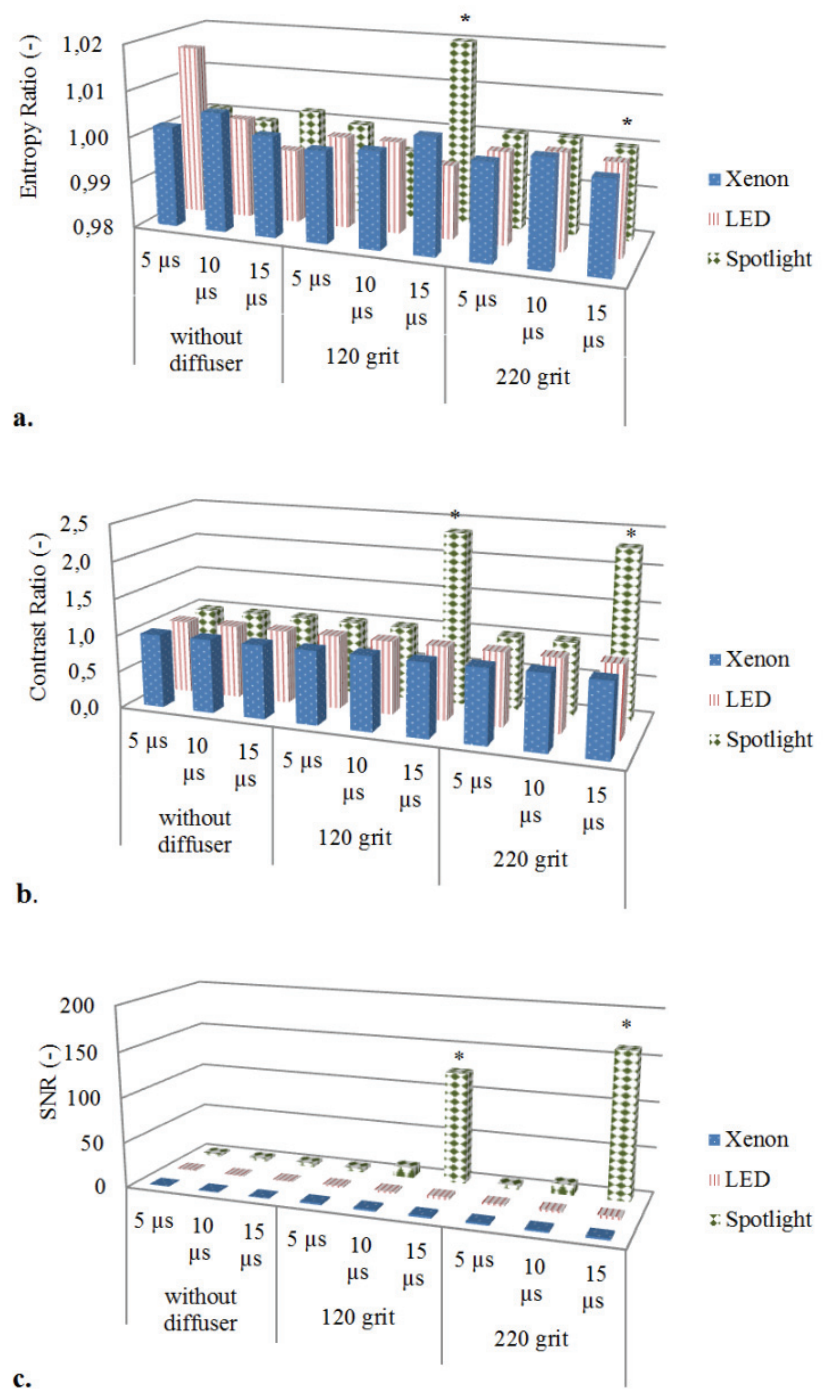

Figure 5. Image quality parameters (a) entropy ratio, (b) contrast ratio, and (c) SNR for the macro video zoom lens for different exposure times and lighting systems. Bars with asterisks are statistically different: * $=\mathbf{p}<0.05$ (Scheffé test).
For the contrast ratio, the three-way interaction light $x$ diffuser $\times$ exposure time was significant $(p<0.001)$. Similar to the entropy ratio, the combinations spotlight $\times 120$ grit diffuser $\times 15 \mu$ s exposure time $(\mathrm{p}<0.001)$ and spotlight $\times 220$ grit diffuser $\times 15 \mu$ s exposure time $(p<0.001)$ had significantly higher contrast ratios than all other combinations. The same conclusion was found for SNR: the combinations spotlight $\times 120$ grit diffuser $\times 15 \mu$ s exposure time $(\mathrm{p}<0.001)$ and spotlight $\times 220$ grit diffuser $\times 15 \mu \mathrm{s}$ exposure time $(\mathrm{p}<0.001)$ had significantly higher SNR than all other combinations.

These results show that for all three image quality parameters, the best results for the macro video zoom lens were found when using the spotlight in combination with a diffuser and an exposure time of $15 \mu$ s. No significant differences were found between the two types of diffusers. Therefore, the combinations spotlight $\times 120$ grit diffuser $\times$ $15 \mu$ s exposure time and spotlight $\times 220$ grit diffuser $\times$ $15 \mu$ s exposure time were selected for further analysis.
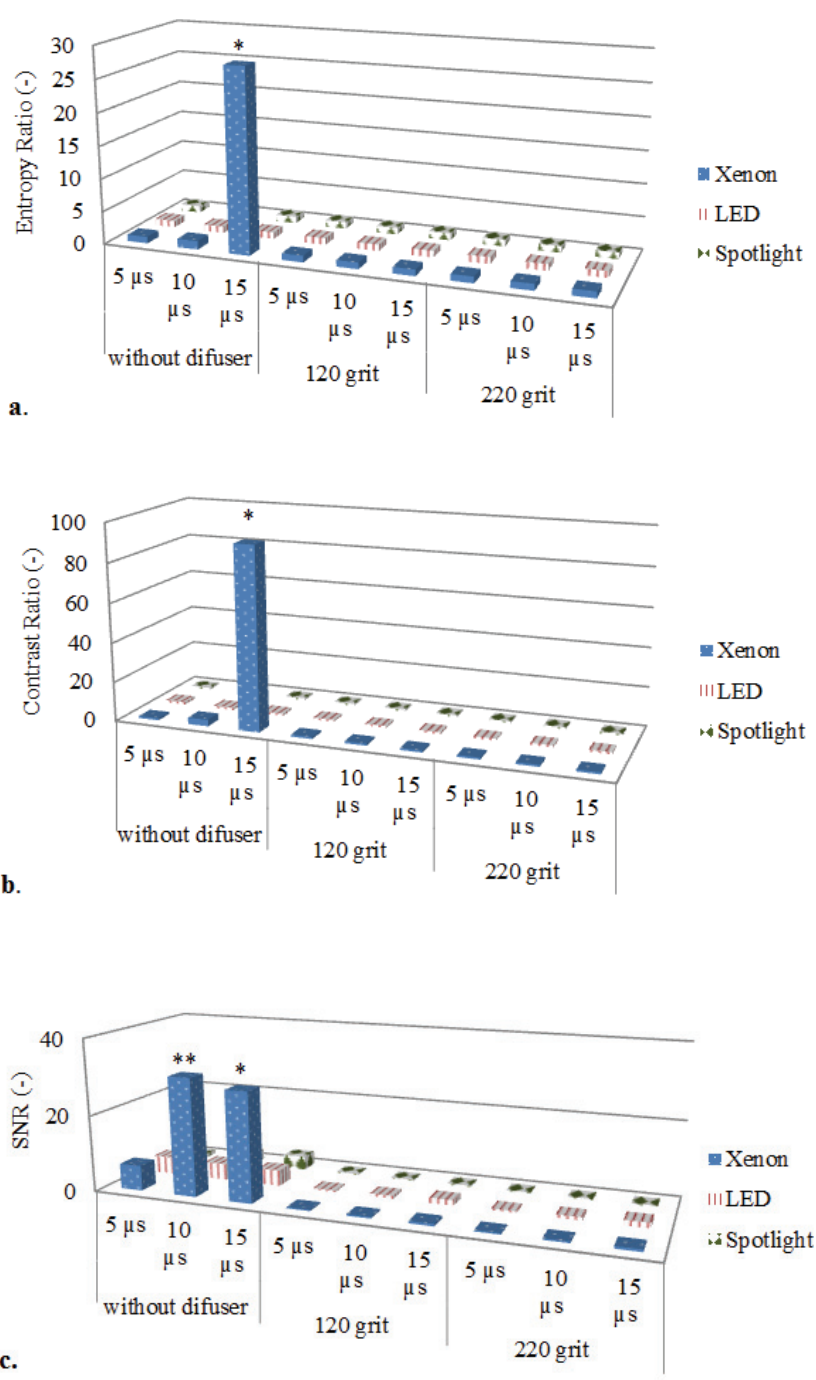

Figure 6. Image quality parameters (a) entropy ratio, (b) contrast ratio, and (c) SNR for the macro video zoom lens for different exposure times and lighting systems. Bars with asterisks are statistically different: $*=\mathbf{p}<0.05$ (Scheffé test) and $* *=p<0.05$ (SNK test). 
For the K2/SC long-distance microscope lens (fig. 6), the three-way interaction light $\times$ diffuser $\times$ exposure time was significant for the entropy ratio $(p<0.001)$ as well as for the contrast ratio $(\mathrm{p}<0.001)$. In both cases, the Scheffé post hoc tests revealed that the combination xenon $\times$ no diffuser $\times 15 \mu$ s exposure time $(p<0.001)$ had significantly higher ratios than all other combinations. For the SNR, the Scheffé test confirmed that the combination xenon $\times$ no diffuser $\times 15 \mu$ s exposure time $(\mathrm{p}<0.001)$ had higher values than all other combinations, while the SNK test showed that the combination xenon $\times$ no diffuser $\times 10 \mu$ s exposure time $(\mathrm{p}<0.001)$ outperformed all other combinations.

These results show that the best results with the K2/SC long-distance microscope lens were always obtained with the xenon light source without a diffuser. For this setup and depending on the statistical test used, the best exposure time was 10 or $15 \mu$ s based on the image quality parameters. The combination xenon $\times$ no diffuser $\times 10 \mu$ s exposure time was selected for further analysis because images taken with the $15 \mu$ s exposure time were visually found to be partly overexposed, which might affect the accuracy of the droplet size measurement. Additionally, the combination LED $\times$ no diffuser $\times 5 \mu$ s was selected as the best low-cost alternative for the expensive xenon light based on the relatively good image quality parameters, although it was not statistically significant.

\section{LIGHT STABILITY AND OVEREXPOSURE RATIO}

An appropriate image acquisition setup for droplet characterization must be capable of delivering an adequate, even, and stable illumination without over- or underexposed areas. In order to achieve this, the four previously selected image acquisition techniques were tested for their light stability and overexposure ratio based on image histograms of ten consecutive images without a droplet (fig. 7). The histograms of both spotlight configurations at $15 \mu \mathrm{s}$

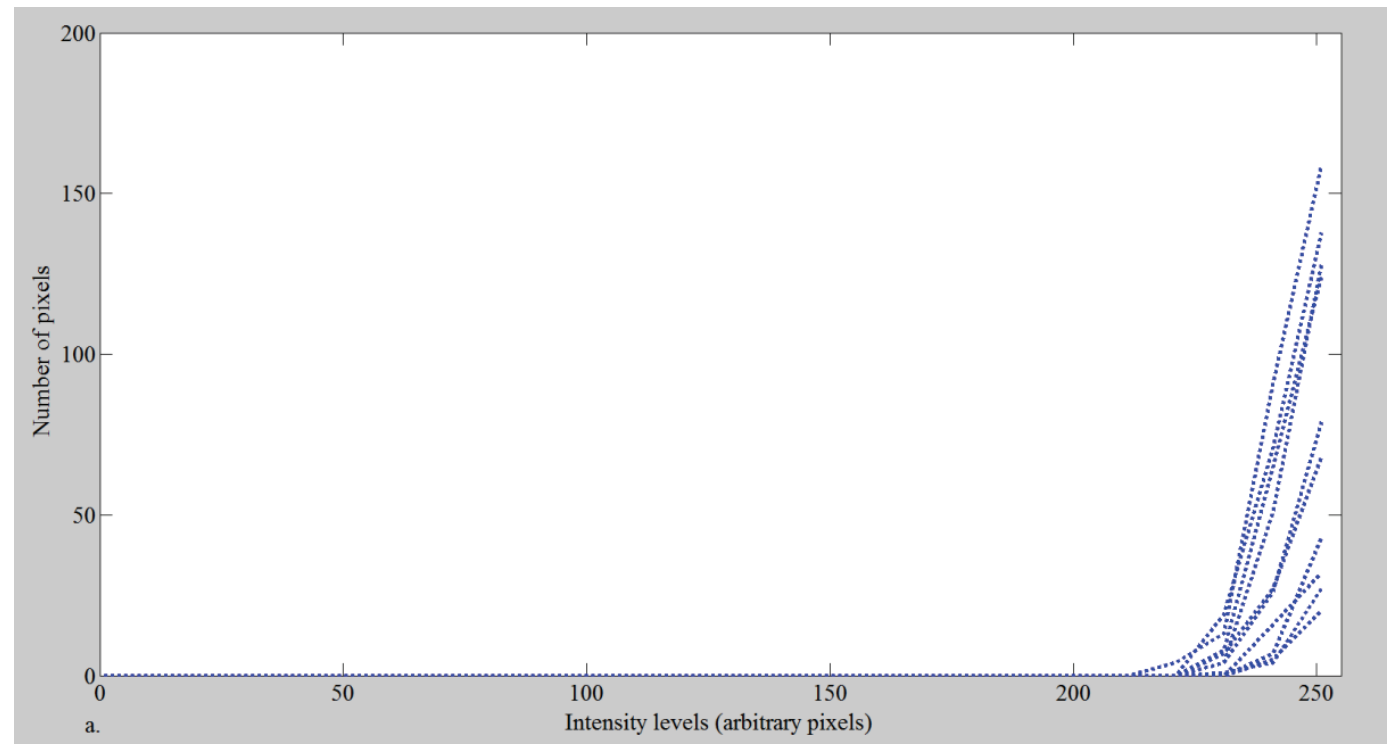

(a)

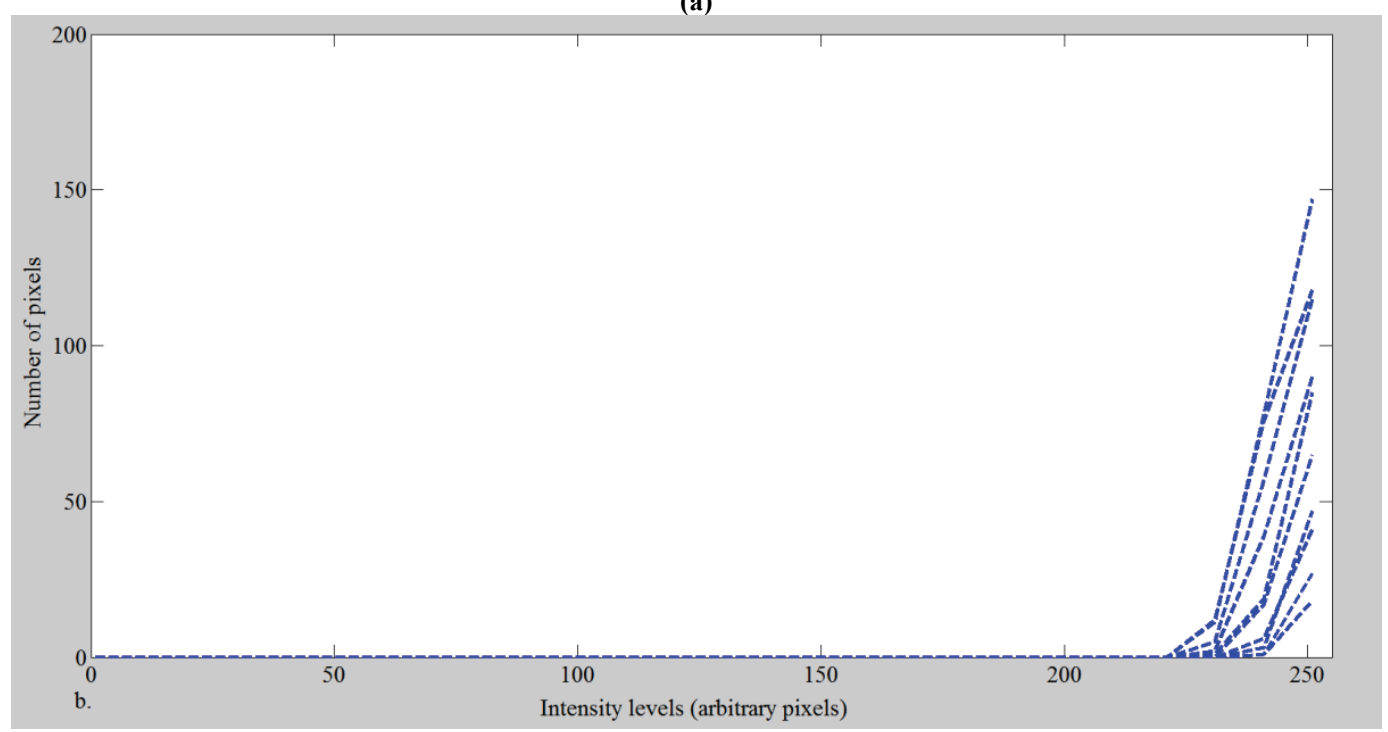

(b)

Figure 7. Histograms of ten consecutive images for two imaging setups: (a) macro video zoom lens $\times$ spotlight $\times 120$ grit diffuser $\times 15 \mu$ s, and (b) macro video zoom lens $\times$ spotlight $\times 220$ grit diffuser $\times 15 \mu$ s. 


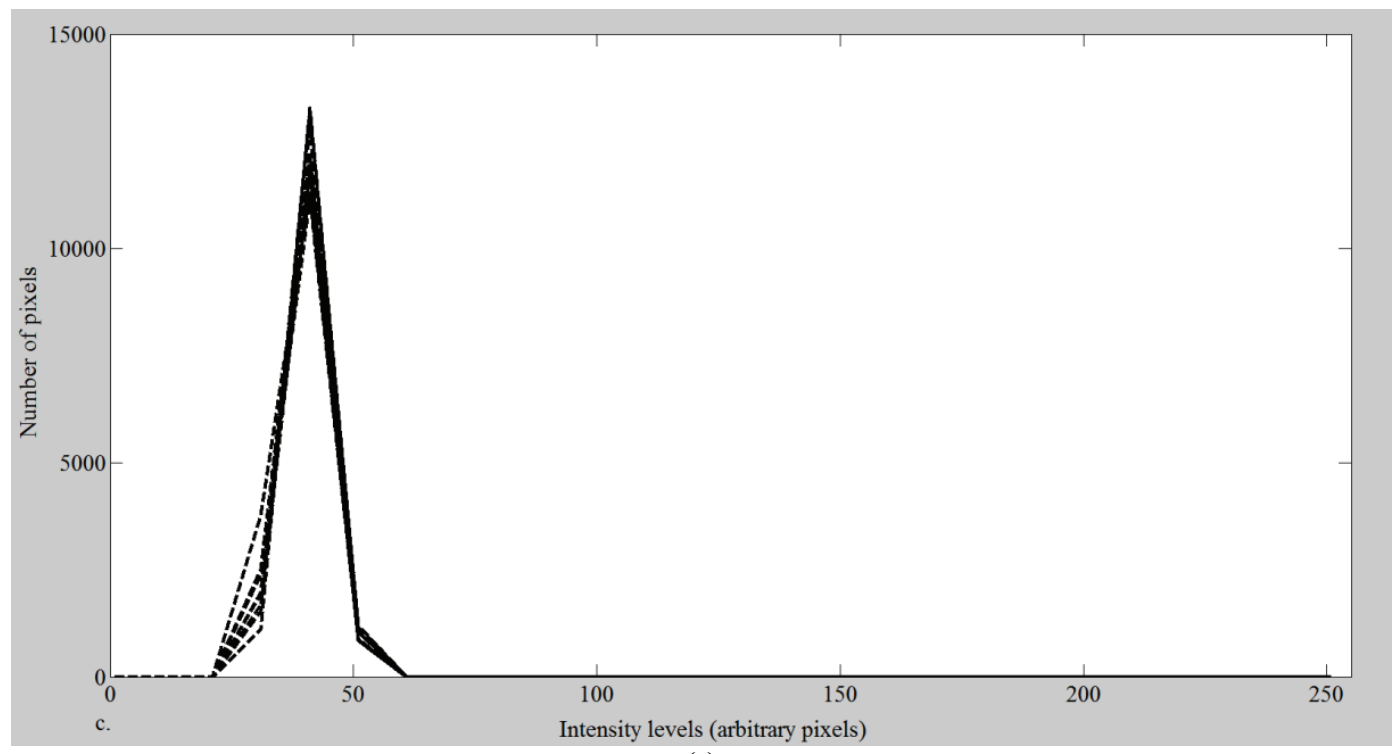

(c)

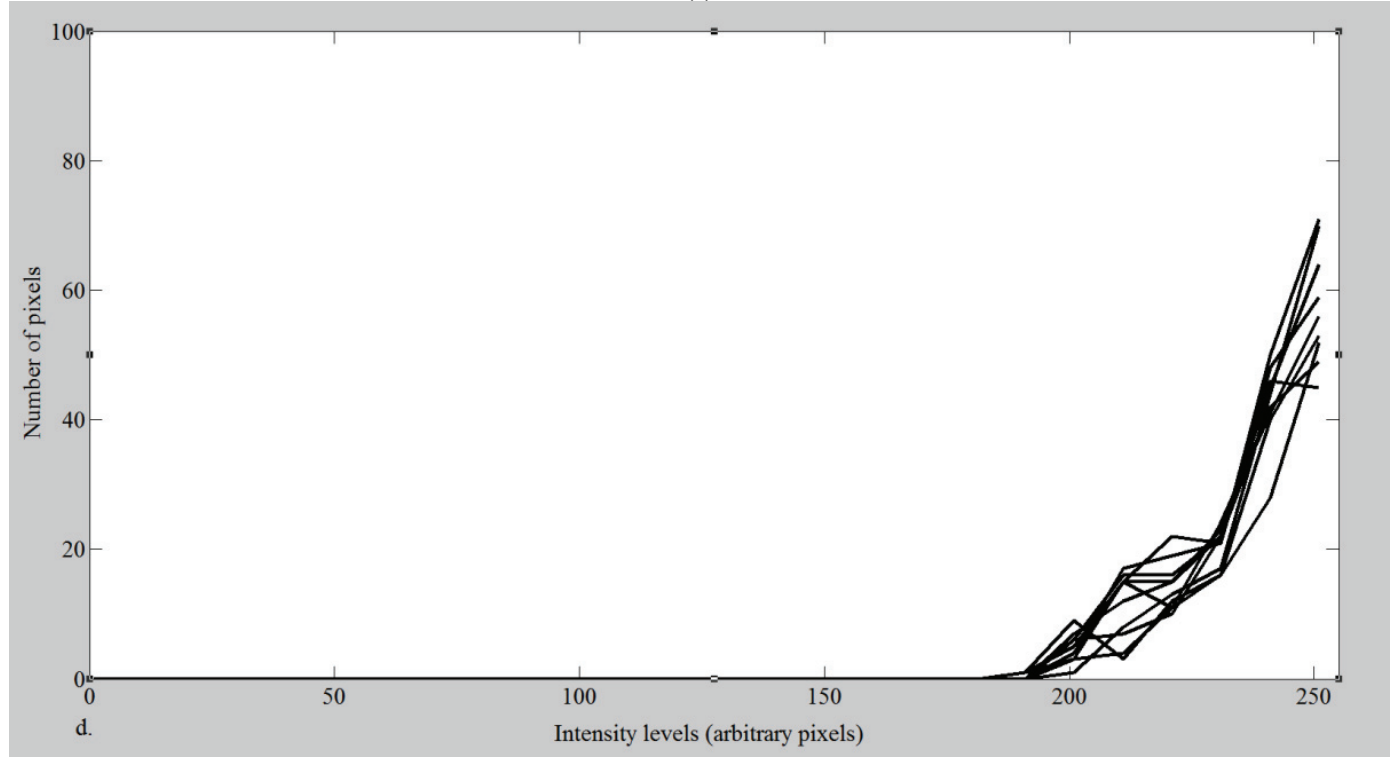

(d)

Figure 7 (continued). Histograms of ten consecutive images two imaging setups: (c) K2/SC long-distance microscope lens $\times$ LED $\times$ no diffuser $\times$ $5 \mu$ s and (d) K2/SC long-distance microscope lens $\times$ xenon $\times$ no diffuser $\times 10 \mu \mathrm{s}$.

exposure time (figs. 7a and 7b) showed light instability, as the curves of different frames did not overlap and were partially overexposed. Because the spotlight was used without an AC/DC converter, light instability was also present for the shorter exposure times of 5 and $10 \mu \mathrm{s}$; however, reducing the exposure time reduced the overexposure ratio (results not shown).

On the other hand, the use of LED lighting with the $\mathrm{K} 2 / \mathrm{SC}$ long-distance microscope lens at $5 \mu$ s gave rise to a clear and stable peak around a gray level of 40 but with relatively dark images (fig. 7c). The xenon light at $10 \mu$ s exposure time appears stable, but the images were overexposed (fig. 7d; note the different scale of the $y$-axis in this figure).

Therefore, additional experiments were included to calculate the image quality parameters with reduced exposure times of $6,7,8$, and $9 \mu$ s using the xenon light (fig. 8a)
Increasing the exposure time considerably increased the SNR and contrast ratio. No correlation was found between the exposure time and the entropy ratio. At the same time and for droplets produced at the same settings, increasing the exposure time reduced the measured droplet size and increased the variation in measured droplet size (fig. 8b) because of the effect of overexposure. To find the optimal exposure time, image histograms were taken with the $\mathrm{K} 2 / \mathrm{SC}$ long-distance microscope lens and xenon light at different exposure times and are presented in figure 9. This figure shows that a $6 \mu \mathrm{s}$ exposure time is optimal, as it gives the brightest images without any overexposure, and the complete histogram is between the 256 intensity levels. In addition, because of the absence of overexposure, no reduction of measured droplet size was observed at $6 \mu \mathrm{s}$ (fig. 8b). 

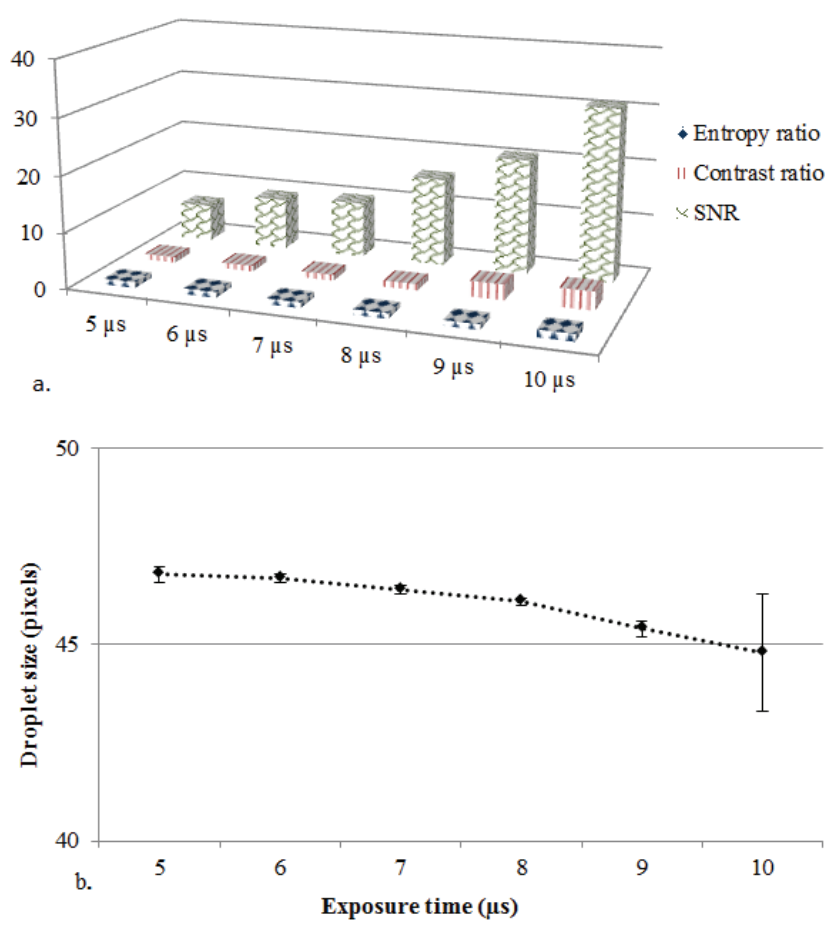

Figure 8. (a) Image quality parameters for $\mathrm{K} 2 / \mathrm{SC}$ long-distance microscope lens and xenon light with no diffuser at 5, 6, 7, 8, 9, and $10 \mu \mathrm{s}$ exposure time and (b) effect of exposure time on droplet diameter measurement.

\section{ACCuracy of Droplet Size Measurement}

From the camera calibration, the calculated pixel size for the setup with the macro video zoom lens was $85.8 \mu \mathrm{m}$. That is too big to measure droplet size accurately, knowing that droplet sizes in a pesticide spray might vary from only a few micrometers up to $1000 \mu \mathrm{m}$. Hence, this setup cannot be used for accurate droplet size measurements, but it can be useful for tracking droplets over longer distances and for measuring macro spray characteristics, as done by Vulgarakis Minov et al. (2014).
For the $\mathrm{K} 2 / \mathrm{SC}$ long-distance microscope lens, the output of the HDevelop software gave a focal length of $67.1 \mathrm{~mm}$, corresponding to a pixel size of $8.2 \mu \mathrm{m}$ and an image size of $10.5 \mathrm{~mm} \times 8.4 \mathrm{~mm}$ for the $1280 \times 1024$ pixel images. Moreover, at $6 \mu$ s exposure time, the droplets moved less than a pixel between frames, which ensured the absence of blurring effects (Ju et al., 2012).

The actual average droplet diameter based on weighing 100 droplets was $386.2 \pm 6.7 \mu \mathrm{m}$, while a value of 390.2 $\pm 4.0 \mu \mathrm{m}$ was found from the image analysis. Hence, the overall precision of the measurements was satisfactory, with a relative measurement error of about $1 \%$ and an absolute error of about $4 \mu \mathrm{m}(1 / 2$ pixel).

\section{CONCLUSION}

The development of an imaging system based on singledroplet experiments was presented using a high-speed camera and a piezoelectric droplet generator. Different lenses, light sources, diffusers, and exposure times were tested. The different imaging setups were evaluated based on image quality parameters (SNR, entropy ratio, and contrast ratio), light stability and overexposure ratio, and the accuracy of the droplet size measurement. The experiments resulted in a good image acquisition and processing system for accurate spray characterization.

The optimal setup for measuring micro spray characteristics (droplet size and velocity) consisted of a high-speed camera with a $6 \mu$ s exposure time, a microscope lens at a working distance of $430 \mathrm{~mm}$ resulting in an FOV of $10.5 \mathrm{~mm} \times 8.4 \mathrm{~mm}$, and a xenon light source used as a backlight without a diffuser.

The high-speed camera with a macro video zoom lens at a working distance of $143 \mathrm{~mm}$ with a larger FOV of $88 \mathrm{~mm}$ $\times 110 \mathrm{~mm}$ in combination with a halogen spotlight and a diffuser was found to have the best potential for measuring macro spray characteristics, such as droplet trajectory, spray angle, and spray shape. With this system, attention

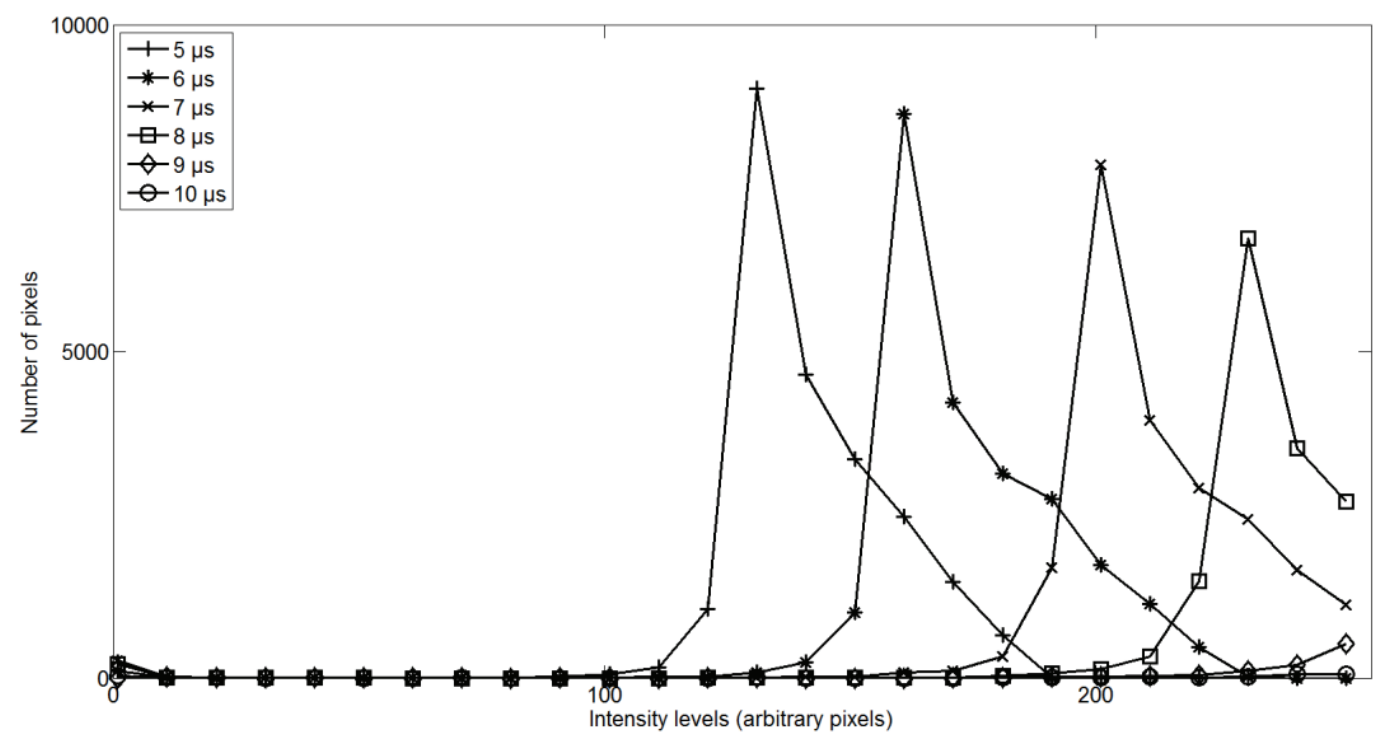

Figure 9. Image histograms using the K2/SC long-distance microscope lens and xenon light with no diffuser at 5, 6, 7, 8, 9, and 10 $\mu$ s. 
should be paid to the light stability.

The developed image acquisition systems can be used to visualize and determine the micro and macro spray characteristics of real pesticide sprays in an accurate and nonintrusive way, as demonstrated by Vulgarakis Minov et al. $(2014,2015)$. In addition, they offer the possibility of studying droplet and spray impact behavior. Future work should focus on further improving the droplet measuring accuracy (e.g., sub-pixel accuracy, calculating depth of field, non-spherical particles, etc.) because of the small, fast droplets in real sprays.

\section{ACKNOWLEDGEMENTS}

This research was funded by the Institute for Agricultural and Fisheries Research (ILVO, Merelbeke, Belgium), the Regional Council of the Burgundy Region (Dijon, France), and Nicéphore Cité Company (Chalon sur Saône, France).

\section{REFERENCES}

Castanet, G., Dunand, P., Caballina, O., \& Lemoine, F. (2013). High-speed shadow imagery to characterize the size and velocity of the secondary droplets produced by drop impacts onto a heated surface. Exp. Fluids, 54, 1489-1506. http://dx.doi.org/10.1007/s00348-013-1489-3.

Cointault, F., Sarrazin, P., \& Paindavoine, M. (2002). Fast imaging system for particle projection analysis: Application to fertilizer centrifugal spreading. Meas. Sci. Tech., 13(7), 1087-1093. http://dx.doi.org/10.1088/0957-0233/13/7/316.

Fan, K. C., Chen, J.-Y., Wang, C.-H., \& Pan, W.-C. (2008). Development of a drop-on-demand droplet generator for onedrop-fill technology. Sensors Actuators A, 147(2), 649-655. http://dx.doi.org/10.1016/j.sna.2008.03.006.

Gonzalez, R. C., Woods, R. E., \& Eddins, S. L. (2004). Digital Image Processing Using MATLAB. Englewood Cliffs, N.J.: Pearson Prentice Hall.

Haralic, R. M., Shanmugam, K., \& Dieinstein, I. (1973). Textural features for image classification. IEEE Trans. Systems Man Cybernetics, 3(6), 610-621. http://dx.doi.org/10.1109/TSMC.1973.4309314.

Hijazi, B., Cointault, F., Dubois, J., Coudert, S., Vangeyte, J., Pieters, J. G., \& Paindavoine, M. (2010). Multi-phase crosscorrelation method for motion estimation of fertiliser granules during centrifugal spreading. Precision Agric., 11(6), 684-70. http://dx.doi.org/10.1007/s11119-010-9193-2.

Hijazi, B., Decourselle, T., Vulgarakis Minov, S., Nuyttens, D., Cointault, F., Pieters, J. G., \& Vangeyte, J. (2012). Chapter 13. The use of high-speed imaging system for applications in precision agriculture. In C. Volosencu (Ed.), New Technologies: Trends, Innovations, and Research (pp. 279-296). Rijeka, Croatia: InTech.

Infinity. (2009). Model K2/SC long-distance microscope system. Boulder, Colo.: Infinity Photo-Optical Company. Retrieved from www.infinity-usa.com/products/instruments/Model_K2.aspx.

Ju, D., Shrimpton, J. S., \& Hearn, A. (2012). A multi-thresholding algorithm for sizing out of focus particles. Particle Particle Syst. Char., 29(2), 78-92. http://dx.doi.org/10.1002/ppsc.201100032.

Kashdan, J. T., Shrimpton, J. S., \& Whybrew, A. (2007). A digital image analysis technique for quantitative characterisation of high-speed sprays. Optics Lasers Eng., 45(1), 106-115. http://dx.doi.org/10.1016/j.optlaseng.2006.03.006.

Kim, H.-H., Kim, J.-H., \& Ogata, A. (2011). Time-resolved highspeed camera observation of electrospray. J. Aerosol Sci., 42(4), 249-263. http://dx.doi.org/10.1016/j.jaerosci.2011.01.007.
Lad, N., Aroussi, A., \& Muhamad Said, M. F. (2011). Droplet size measurement for liquid spray using digital image analysis technique. J. Appl. Sci., 11(11), 1966-1972. http://dx.doi.org/10.3923/jas.2011.1966.1972.

Lam, K. H., Sun, C. L., Kwok, K. W., \& Chan, H. L. W. (2009). Piezoelectric dispenser based on a piezoelectric-metal-cavity actuator. Rev. Sci. Instruments, 80(7), 075110. http://dx.doi.org/10.1063/1.3187220.

Lecuona, A., Sosa, P. A., Rodriguez, P. A., \& Zequeira, R. I. (2000). Volumetric characterization of dispersed two-phase flows by digital image analysis. Meas. Sci. Tech., 11(8), 11521161. http://dx.doi.org/10.1088/0957-0233/11/8/309.

Lee, E. R. (2002). Microdrop Generation. Boca Raton, Fla.: CRC Press.

Lefebvre, A. H. (1989). Atomization and Sprays. New York, N.Y.: Hemisphere Publishing.

Li, E. Q., Xu, Q., Sun, J., Fuh, J. Y. H., Wong, Y. S., \& Thoroddsen, S. T. (2010). Design and fabrication of a PET/PTFE-based piezoelectric squeeze mode drop-on-demand inkjet printhead with interchangeable nozzle. Sensors Actuators A, 163(1), 315-322. http://dx.doi.org/10.1016/j.sna.2010.07.014.

Malot, H., \& Blaisot, J.-B. (2000). Droplet size distribution and sphericity measurements of low-density sprays through image analysis. Particle Particle Syst. Char., 17(4), 146-158. http://dx.doi.org/10.1002/1521-4117(200012)17:4<146::AIDPPSC146>3.0.CO;2-4.

Massinon, M., \& Lebeau, F. (2012). Comparison of spray retention on synthetic superhydrophobic surface with retention on outdoor grown wheat leaves. Aspects Appl. Biol. 114, 261-268. http://dx.doi.org/10.13140/2.1.1465.5367.

Materka, A., \& Strzelecki, M. (1998). Texture analysis methods: A review. COST B11 report. Lodz, Poland: Technical University of Lodz, Institute of Electronics.

Miller, P. C. H., \& Ellis, M. C. B. (2000). Effects of formulation on spray nozzle performance for applications from ground-based boom sprayers. Crop Prot., 19(8-10), 609-615. http://dx.doi.org/10.1016/S0261-2194(00)00080-6.

Nuyttens, D., Baetens, K., De Schampheleire, M., \& Sonck, B. (2007). Effect of nozzle type, size, and pressure on spray droplet characteristics. Biosystems Eng., 97(3), 333-345. http://dx.doi.org/10.1016/j.biosystemseng.2007.03.001.

Nuyttens, D., De Schampheleire, M., Verboven, P., Brusselman, E., \& Dekeyser, D. (2009a). Droplet size and velocity characteristics of agricultural sprays. Trans. ASABE, 52(5), 1471-1480. http://dx.doi.org/10.13031/2013.29127.

Nuyttens, D., Taylor, W. A., De Schampheleire, M., Verboven, P., \& Dekeyser, D. (2009b). Influence of nozzle type and size on drift potential by means of different wind tunnel evaluation methods. Biosystems Eng., 103(3), 271-280. http://dx.doi.org/10.1016/j.biosystemseng.2009.04.001

Reichard, D. L., Cooper, J. A., Bukovac, M. J., \& Fox, R. D. (1998). Using a videographic system to assess spray droplet impaction and reflection from leaf and artificial surfaces. Pesticide Sci., 53(4), 291-299.

http://dx.doi.org/10.1002/(SICI)10969063(199808)53:4<291::AID-PS773>3.0.CO;2-W.

Rhodes, M. (Ed.). (1998). Introduction to Particle Technology. Hoboken, N.J.: John Wiley and Sons.

Riefler, N., \& Wriedt, T. (2008). Generation of monodisperse micron-sized droplets using free adjustable signals. Particle Particle Syst. Char., 25(2), 176-182. http://dx.doi.org/10.1002/ppsc.200700038.

Šikalo, S., Tropea, C., \& Ganic, E. N. (2005). Impact of droplets onto inclined surface. J. Colloid Interface Sci., 286(2), 661-669. http://dx.doi.org/10.1016/j.jcis.2005.01.050.

Stafford, J. V. (2000). Implementing precision agriculture in the 
21st century. J. Agric. Eng. Res., 75(3), 267-275. http://dx.doi.org/10.1006/jaer.2000.0577.

Stainier, C., Destain, M. F., Schiffers, B., \& Lebeau, F. (2006). Droplet size spectra and drift effect of two phenmedipham formulations and four adjuvants mixtures. Crop Prot., 25(12), 1238-1243. http://dx.doi.org/10.1016/j.cropro.2006.03.006.

Switzer, G. L. (1991). A versatile system for stable generation of uniform droplets. Rev. Sci. Instruments, 62(11), 2765-2771. http://dx.doi.org/10.1063/1.1142211.

Teske, M. E., Thistle, H. W., Hewitt, A. J., \& Kirk, I. W. (2000). Conversion of droplet size distributions from PMS optical array probe to Malvern laser diffraction. In Proc. 8th Intl. Conf. Liquid Atomization and Spray Systems (ICLASS 2000). Retrieved from www.fs.fed.us/foresthealth/technology/pdfs/ConversionProbeDi ffractiion.pdf.

Tuceryan, M., \& Jain, A. K. (1998). Texture analysis. In C. H. Chen, \& L. F. Pau (Eds.), The Handbook of Pattern Recognition and Computer Vision (2nd ed., pp. 207-248). Singapore: World Scientific Publishing.

Ulmke, H., Wriedt, T., \& Bauckhage, K. (2001). Piezoelectric droplet generator for the calibration of particle-sizing instruments. Chem. Eng. Tech., 24(3), 265-268. http://dx.doi.org/10.1002/1521-4125(200103)24:3<265::AIDCEAT265>3.0.CO;2-4.

Vangeyte, J. (2013). Development and validation of a low-cost technique to predict spread patterns of centrifugal fertiliser spreaders. PhD diss. Leuven, Belgium: Katholieke Universiteit
Leuven, Department of Biosystems.

Vulgarakis Minov, S., Cointault, F., Vangeyte, J., Pieters, J. G., \& Nuyttens, D. (2013). Measurement of single droplet characteristics using high-speed imaging techniques. In Proc. IASTED Intl. Conf. Signal Processing, Pattern Recognition, and Applications (SPPRA 2013) (pp. 321-326). Calgary, Alberta, Canada: ACTA Press.

Vulgarakis Minov, S., Cointault, F., Vangeyte, J., Pieters, J. G., \& Nuyttens, D. (2014). Spray nozzle characterization using a backlighted high-speed imaging technique. Aspects Appl. Biol., 122, 353-361.

Vulgarakis Minov, S., Cointault, F., Vangeyte, J., Pieters, J. G., \& Nuyttens, D. (2015). Droplet generation and characterization using piezoelectric droplet generator and high-speed imaging techniques. Crop Prot., 69, 18-27.

Yang, J. C., Chien, W., King, M., \& Grosshandler, W. L. (1997). A simple piezoelectric droplet generator. Exp. Fluids, 23(5), 44544. http://dx.doi.org/10.1007/s003480050134.

Zabkiewicz, J. A. (2007). Spray formulation efficacy: Holistic and futuristic perspectives. Crop Prot., 26(3), 312-319. http://dx.doi.org/10.1016/j.cropro.2005.08.019.

Zwertvaegher, I. K., Verhaeghe, M., Brusselman, E., Verboven, P., Lebeau, F., Massinon, M., Nicolai, B. M., \& Nuyttens, D. (2014). The impact and retention of spray droplets on a horizontal hydrophobic surface. Biosystems Eng., 126, 82-91. http://dx.doi.org/10.1016/j.biosystemseng.2014.07.013. 